\author{
Ardiana Mali \\ University “A. Xhuvani” of Elbasan, Albania \\ e-mail: ardiana.mali@gmail.com
}

\title{
Prevention of Violence and Bullying in the School
}

\begin{abstract}
Almost every student during his or her education is involved or influenced by violence and the phenomenon of bullying, which causes great psychosocial consequences to children. The purpose of this study is to analyze through a qualitative analysis management methods and intervention strategies used in schools to prevent and reduce violence and bullying among students.
\end{abstract}

Keywords: prevention, violence, bullying, strategies

\section{Introduction}

Nowadays, violence and bullying there are common phenomenon. The violence among children exists in various forms, while the issue of bullying has attracted the attention of many researchers all over the world. The first scientific studies regarding the violent behavior are carried out more than forty years ago (Olweus, 1973). According to many authors bullying includes "all behaviors that are violent and intentionally repeated against a weak person and without any previous provocation (Olweus, 2003, Brown et al., 2005)". In these studies bullying is categorized into several types of violence such as verbal, social, sexual, and virtual/cyber. Verbal violence is straight forward and therefore easy to distinguish. This type of violence includes swearing, insults, gossip, etc. Physical violence is also straight forward and involves pushing, colliding, kicking or 
punching, or using other items to hit. Social violence includes neglect or ignorance as well as leaving outside the group, exclusion or leaving out of the game (Crick \& Grotpeter, 1996). Sexual Violence involves unwanted touches, harassing messages with verbal or shameless sexual allegations. Virtual/cyber violence is mostly not straightforward. This type of violence includes aggression in the form of phone messages, rumors about the person, as well as leaving outside the group of persons or exclusion from social networks (Keith \& Martin, 2005, Hindjua \& Patchin, 2010). Some researchers to understand violence in schools used the ecological model (Bronfenbrenner, 1979). The factors affecting children's school problems may include several levels. Family members, teachers, friends and the community have a major impact on the child. Parents have an active role in their children's school. Parents' participation in different school activities as well as parental and teacher collaboration have a positive effect on the child development because various elements of his Microsystems interact together. Ecological levels are used as a way to clarify different values, goals and strategies for interference with each level of analysis (Rappaport, 1977). Child development may be adversely affected if different elements of its Microsystems act in conflict with one another. Bullying has negative effects on children in school. A study carried out in the United States shows that about $30 \%$ of children in public schools are victims of bullying (Nansel, et al. 2001). According to an international study carried out during 2005-2006 by Health Behavior in School-Aged Children (HBSC) in schools from 40 countries from Europe and North America reported that $45.2 \%$ of boys and $35.8 \%$ of girls were affected by bullying.

In another study carried out in Albania it is noticed that $48 \%$ of the students were physically abused by their classmate and other students in the school (Th. Karaj et al., 2006). The violence and bullying in schools have a negative impact on the academic performance of students. The academic progress is almost impossible for the majority of students in environments characterized by aggression, violence, lack of civilization, and antisocial behaviors.

\section{Methodology}

A qualitative methodology is used in this study. 
In this study are included 20 students from 14 to 16 years old who attend the public school in the city of Elbasan. All these students are victims of bullying in school. Also, 20 teachers from four public schools are included in this study. The period of study lasts from September 2018 to April 2019. The semi-structured interviews instruments are used in the study with students and their teachers. Another instrument used is the observation of children in their behaviors during their free time in the classroom and yard school. The interviews used with the teachers consist of 12 open argumentation questions. The children were observed during the role-playing and group work in schools in order to observe if elements of their behavior are affected by bullying.

Some initial analysis of the interviews with teachers were carried out and then the observation data realized with the children bullying victims were analyzed. The qualitative approach of the study is more realistic and does not adhere to any particular study paradigm in general, (Broun \& Clarke, 2006). Qualitative analysis as a practical and useful search tool that can provide us with detailed data is used. Twenty teacher's interviews, about the reaction and behavior of aggressive students and students who are victims of bullying as well as on strategies for preventing violence and bullying in school were analyzed.

\section{Results and Discussions}

The findings according to teachers' interview.

The first interview question is: How do you think, bullying has been present during the last year in your school? $80 \%$ of teachers answered that there is no bullying in their school. This answer comes from the fact that the persistent harassment, frustration and insults among children were common and somewhat acceptable for this age group. While 10\% of teachers claimed that bullying in their school exists and the hardest form is physical aggression.

The second interview question is: How are the students, victims of bullying and how do you think they should be treated? Teachers claimed that students, victims of bullying are mostly tolerant of other peoples' behaviors, have a low self-confidence and are slightly associated with other children. Sullivan (2000) found that the victims of bullying have difficulties in creating social relations and tend to be less successful in the 
future. In our study $95 \%$ of teachers say they try to help and stay close to the students who are victims of bullying. About $5 \%$ of teachers blame students who are victims of bullying.

One of the teachers says:

"Child victims are the self-guilty. They do not have to comply with the requirements of violent children, but they have to respond in the same way".

Regarding the question, how are the violent students, and how do you think they should be treated? Teachers claim that these students, are tough, never apologize, blame others, think they are always right and require a lot of attention. $100 \%$ of teachers answered that aggressive students do not have warmth and love in the family. The teachers claim that violent students and bullies, in their school, in general come from families with high levels of aggression and with antisocial behavior of parents, sisters or brothers. Some of them are with divorced parents, with one or two parents prisoners, with abusive parents of substances and alcohol. Parents of violent children are almost never interested in the behavior and academic performance of their children in the school, (Juvonen et al., 2001). They claim that bullying and antisocial behavior originate from lack of attention and care in the family. The teachers think that these children should be educated and taught with pro-social behavior. At school, violent students should given the lack of parent's warmth.

Regarding solving problems that arise from the bullying, $80 \%$ of the teachers reported that bullying is an uncommon phenomenon, and as such, students should not be left to solve problems themselves in all situations.

A teacher shows what happened in her school:

"Albi learns in class eight. He lives with his mother and his little brother. His father was dead when Albi was 3 years old. Albi was offended in classroom and social networking for a year by his classmat, called Ben, No one paid much attention to Ben's persistent insults against Albi. One day Albi after the first lesson strikes Ben, bleeding in the foot". 
While, if the teachers had been careful to understand earlier verbal violence among the students would have helped to solve the problem, and this event would have been prevented.

Regarding the question what can be the most effective strategies that can be used to prevent violence and bullying in school result that $80 \%$ of the teachers say that in their school they have a clear discipline rules of students in the school and this regulation is applied consistently by the students. $100 \%$ teachers, reported that training process developed by the school psychologist has helped them to address the problems that arise from violence among children in the school.

Children victims of bullying were observed during their free time in the yard's school. During the play-role and the work in group, regarding the behaviors they show the interaction with others. By observing the children, it resulted that they performed many kind of behaviors during interaction with their friends. These children were lonely, did not easily become part of the game, easily accepted the defeat in the game and immediately withdrew from the game. During the observation it was noted that in general they showed good behaviors with other children, mostly smaller than themselves, but it is difficult to take initiative and responsibility while working in the group. According to school psychologist those behaviors were a result of violence and bullying.

These children were observed two months later, following the interventions made by the relevant school structures (school directorate, teachers, school psychologist, nurse, school guard). The development of individual and group sessions by the school psychologist with children victims of bullying, their involvement in group activities helped them to increase self-estimation and orientated them how to solve the problems. Parents' involvement in various school-based activities by school principal, teachers and students also enhances effective interaction between family, school and students. The data about the child observation showed that the management and use of the appropriate strategies reduced violence and bullying in school.

\section{Conclusions}

Based on the data of this qualitative study can be reached in some conclusions 
- The prevention of bullying requires effort at many ecological levels of intervention.

- Everyone in the school environment has the right to be protected from any form of violence that endangers his physical and moral mental health.

- An effective interaction between school, family, and psychologist plays an important role in both preventing and reducing violence and bullying in the school.

- The children have the right to study in school and feel safe.

- The continuous development and implementation of school discipline regulations has an important impact on the bullying prevention.

\section{Recommendations}

- School discipline policies should be clearly structured and implemented continuously.

- The school psychologist, together with the school's staff, should organize ongoing effective training to prevent bullying including all actors.

- Teachers at school should pay attention to changing student's behaviors and helping students solve problems.

- Parents should evaluate seriously each kind of behavior and complaint of their children by listening carefully and assisting them in solving the problem.

- A national strategy for prevention and reduction of violence and bullying in Albanian schools should be drafted.

\section{References}

Braun, V. \& Clarke, V. (2006), Using thematic analysis in psychology, "Qualitative Research in Psychology", 3 (2), pp. 77-101.

Bronfenbrenner U. (1979), The ecology human development, Cambridge, MA Harvard University.

Brown S. et al., (2005), Bullying perspectives: Experiences, attitudes, and recommendations of 9 to 13 year olds attending health education centers in the United States, “Journal of School Health", 75(10), 384-392. 
Crick N. R., \& Grotpeter J. K. (1996), Children's treatment by peers: Victims of relational and overt aggression, "Development and Psychopathology", 8, 367-380.

Juvonen J. et al. (2001), Self-views versus peer perception of victim status among early adolescents [in:] Juvonen, J. \& Graham, S. (Ed.) Peer Harassment in School: The plight of the vulnerable and victimized, New York: Guilford Press.

Hindjua S. \& Patchin J.W. (2010), Cyber bullying: An exploratory analysis of factors related to offending and victimization, "Deviant Behavior", 29, pp. 129-156.

Karaj. Th. et al., (2007), Violence against the children in Albania, UNICEF, Development Human Resources.

Keith, S. \& Martin M. (2005), Cyber bullying: Creating a culture of respect in a cyber world, "Reclaiming Children and Youth", 13(4), 224-228.

Nansel T. R. et al., (2001), Bullying behaviors among US youth: Prevalence and association with psychosocial adjustment, "Journal of the American Medical Association", 285, pp. 2094-2100.

Olweus D. (1973, a), Personality and agression. Symposium on motivation, Lincoln: University of Nebraska Press.

Olweus D. (2003), A profile in bullying, "Educational Leadership", 60(6), pp. 12-17. Rappaport J. (1977), Community psychology: Values, research and action, New York.

Sullivan K. (2000), The anti-bullying handbook, N.Y: Oxford University Press. 
